Running Head: Witch

\title{
“Are You a Good Witch or a Bad Witch?": An Exercise in Suspending Judgment when Interacting with "Difficult" People
}

\author{
John S. Seiter \\ Department of Languages, Philosophy, and Communication Studies \\ Utah State University \\ Logan, Utah 84322-0720 \\ 435-797-0138 \\ john.seiter@usu.edu
}

\author{
Christian R. Seiter \\ Department of Communication \\ George Mason University \\ Fairfax, VA 22030-4444
}

(435) 232-2987

cseiter@gmu.edu

The corresponding author is John S. Seiter (john.seiter@usu.edu). The authors declare no conflict of interest. 
Witch 2

\section{“Are You a Good Witch or a Bad Witch?": An Exercise in \\ Suspending Judgment when Interacting with "Difficult" People}

Courses: Interpersonal Communication, Health Communication

Objectives: In this single-class activity, students gain awareness and practice in suspending judgments about "difficult" people in order to understand the reasoning behind certain objectionable behavior.

Keywords: Person-Centeredness, Perception, Perspective-Taking, Suspending Judgment, Fundamental Attribution Error

\section{Rationale}

The ability to withhold judgment when interacting with others is a cornerstone of communication competence (e.g., see Wood, 2016), and yet, can be a challenging skill to put into practice. Indeed, it's one thing to delay evaluation when attempting to understand a person we care about, but what if the other person is difficult or hateful, espousing views that are morally different from our own? This is an especially important skill for students whose future careers may depend on maintaining fiduciary relationships, which require one person to act for the benefit of another (e.g., patient-provider and attorney-client relationships).

Despite the importance of withholding judgment, teaching it can prove challenging. In our experience, actual cases can provoke intense reactions, perhaps because the stakes are so high. Consider, for example, the real cases of a Jewish physician treating an unapologetic Nazi (Sussman, 2016), or a surgeon who dutifully treated terrorists after they'd murdered his family (see Hall, 2009). With that in mind, this exercise was designed to provide a less threatening introduction into confronting such cases. Specifically, students are asked to (re)consider the perspectives of well-known fictional characters, often making surprising discoveries along the 
Witch 3

way. Their goal is not to condone or even validate reprehensible acts. Rather, the aim is to engage in the experience of coming to understand such individuals rather than "shutting off."

\section{The Activity}

Overview: Students create, present, and discuss case studies of characters while considering the character's point of view.

Materials and preparation: Appendix A includes a cast of characters that students might recognize as some of the most notorious "villains" in pop culture history. You'll also find one sample biography (for Captain Hook) along with hints for students' consideration (for material on all the characters, contact the authors).

Procedures: Begin by asking your students what it means to be person-centered, and use the discussion to introduce topics such as perspective-taking, being other-oriented, and listening to understand. Are there roadblocks to practicing such skills? Here you might discuss obstacles to effective perception, including the fundamental attribution error and evaluative listening. How might such obstacles be overcome? Can viewing someone from an alternative point of view influence the impressions we form?

By way of example, point to pop culture, asking students who have seen The Wizard of $\mathrm{Oz}$ (LeRoy \& Fleming, 1939) to describe, in a word or two, the Wicked Witch of the West as seen from Dorothy's perspective (e.g., ugly, scary, vicious, evil), and to identify how such impressions might have been formed (e.g., cackling, lighting the scarecrow on fire). Next, ask students who have seen (or read) Wicked, a prequel to $O z$, whether their impressions of that same witch changed, and, if so, why. For example, in Wicked (McGuire, 1995), Elphaba (the "wicked" witch) is largely a sympathetic character. She experiences ostracism due to her skin color, demonstrates passion for rescuing animals, and her descent into "wickedness" resembles more of a departure from sanity than a penchant for evil. 
Witch 4

Following this discussion, tell students it is their turn to practice imagining alternative points of view toward other characters with questionable reputations. Their goal is not to approve or disapprove of what their character has done, but rather to suspend judgment long enough to consider alternative points of view (see Wood, 2016). Form small groups and provide each group with a character, the character's brief biography, questions to ponder (see Appendix A), and twenty minutes to create a case study. The study should include: 1) a background of the character; 2) alternative explanations (i.e., other than personality traits such as "bad" or "evil”) for the character's behavior; and 3) possible measures that might have been taken to prevent such behaviors. The explanations might be factual (e.g., the Giant was the victim of a beanstalkclimbing burglar), hypothesized (e.g., does being called "Scar" perpetuate a self-fulfilling prophecy?), and/or speculative within reason (e.g., perhaps young Cruella was mauled by Dalmatians). To help with this task, read students an example case (see Appendix B). In addition, although students' imaginations and character biographies should provide enough material, we permit them to use electronic devices for additional research, which can prove handy. Using her cell phone, for example, one of our students discovered that Scar's original name was "Taka," which means "dirt" or "trash" in Swahili (see Lindsay, 2015). After students have created their accounts, provide five minutes per group to present their findings.

Debriefing: After the presentations, ask students what they observed. Was coming up with alternative explanations difficult? Ask what might be learned from this exercise, helping students understand how different points of view and additional information (e.g., backstories) can lead to drastically different impressions. Is there a benefit to suspending judgment for the sake of understanding someone whom might otherwise be labeled villainous?

From here, explore how features of this exercise might apply to "real life" interactions. Ask students to share examples in which their negative evaluations of a person changed after gathering more information. This is also a good time to examine communication concepts. For 
Witch 5

example, does considering alternative viewpoints help overcome the fundamental attribution error? Do labels such as "villain” influence perceptions? Might such labels lead to self-fulfilling prophecies?

In addition, ask students to imagine future contexts that might call for this skill. What professions might require them to deal with "difficult" people? This might serve as a transition into talking about how to approach such cases in medical, legal or other contexts, and then to a discussion of ethics. For instance, should professionals be expected to treat patients whom they find to be despicable? Is it possible to suspend judgment without sacrificing your values? Does considering another perspective require you to agree with another person? After listening to a person, when is it appropriate to disagree? At this point, consider introducing actual case studies (e.g., Sussman, 2016) and the ways in which the focal concepts in this exercise apply.

\section{Conclusion and Appraisal}

Our motivation for creating this activity emerged from a combination of belief and experience. On one hand, we believed students could benefit from understanding and practice in withholding judgment, especially when faced with people they perceive as "difficult." On the other, when presented with actual cases, our students often resisted, unable to see beyond their initial negative reactions. Based on our observations alongside anonymous feedback from 76 students at two universities, we believe this activity helped overcome such obstacles. After completing it, our students were more enthusiastic in their discussion of "real life" cases. In addition, students seemed to appreciate how abstract concepts might be applied. As one noted, "Getting to go through this in a safe way with fictional characters helped me see the dangers of the fundamental attribution error." Others noted, "I like that it was a fun and interactive way to apply what we have been learning in class," "I learned not to jump to harsh conclusions about an individual if I don't know their story," and "I like how it truly challenged us to take a step backward and not stigmatize." 
Witch 6

Despite the activity's strengths, one limitation is that success depends, to some degree, on the nature of the characters. If you decide to add your own "villains," it is best to stay away from characters whose actions are too gruesome (e.g., Hannibal Lecter). Alternatively, you might let your students select their own villains, although, in our experience, this can sometimes lead to a cast of obscure villains with one-dimensional backgrounds. To extend the exercise, you might ask students to imagine they have a time machine and are in a position of influence (perhaps as a counselor or trusted teacher) over these "villains" at an earlier stage of their lives. Ask them to construct messages using empathetic and descriptive, rather than evaluative, language that might help the "villains" feel heard and, perhaps, even alter their behavior.

In addition, although we designed this activity with interpersonal and health communication courses in mind, it not hard to imagine how it might be adapted to other classes. For example, the activity could be useful in a course or unit on intercultural communication to examine the nature of myths and stories from various cultures. Moreover, in public speaking or persuasion courses that feature units on audience analysis, the activity could help students understand why people may have different viewpoints.

Finally, it is important to reiterate that the purpose of the exercise is not to condone despicable actions committed by these characters, but to seek to understand possible reasons behind those actions. The authors' hope is that the use of this exercise will inspire important conversations about suspending judgment that could later be applied to more real-life scenarios. 
References

Disney, W. (Producer), Geronimi, C., Jackson, W, \& Luske, H. (Directors). (1953). Peter Pan [Motion picture]. United States: Disney.

Hall, W. J. (2009). The intervention of Saint George. Journal of the American Medical Association, 301, 2076-2077. doi: 10.1001/jama.2009.676

LeRoy, M. (Producer), \& Fleming, V. (Director). (1939). The Wizard of Oz. [Motion picture]. United States: Metro-Goldwyn-Mayer.

Lindsay, D. (2015, March 28). The Lion King fact that will blow your mind: what was Scar's real name in the Disney classic? Metro. Retrieved on March 10, 2019 from https://metro.co.uk/2015/03/28/the-lion-king-fact-that-will-blow-your-mind-what-wasscars-real-name-in-the-disney-classic-5125432/

McGuire, G. (1995). Wicked: The life and times of the Wicked Witch of the West. New York: Harper Collins.

Sussman, B. L. (2016). The Nazi patient. Annals of Internal Medicine, 164, 507-508. doi: 10.7326/M15-1759

Wood, J. T. (2016). Interpersonal communication: Everyday encounters. Boston, MA: Cengage. 
Appendix A

Cast of Characters Plus Example Background and Questions for Captain Hook

For biographies and questions on Scar, Giant, Vader, Cruella, and Sid, contact the authors.

\section{Captain Hook from Peter Pan}

Hook, the captain of a pirate ship, is known as a sadistic and vengeful leader, mistreating his crewmembers to demonstrate power. He is obsessed with conquering his nemesis, Peter Pan, who consistently thwarts Hook's plans. In one traumatizing incident, Pan cut off Hook's hand as a practical joke and fed it to Tick-Tock, a crocodile who swallowed an alarm clock years before. After this attack, Hook used a hook in place of his hand. Whenever he hears a clock ticking, he experiences physiological symptoms, including panic attacks. Hook frequently kidnaps children in the hopes of luring Pan to his ship to finish him off, but is thwarted every time (Disney, Geronimi, Jackson, \& Luske, 1953).

Questions to consider:

How might traumatic pasts shape future behaviors? How might leadership pressures influence one's behavior? How might living with a disability affect one's life?

2. Scar from The Lion King

3. The Giant from Jack and the Beanstalk

4. Darth Vader/Anakin Skywalker from Star Wars

5. Cruella de Vil from 101 Dalmations

6. Sid from Toy Story

7. The Green Goblin/Norman Osborn from Marvel Comics

8. Draco Malfoy from Harry Potter

9. Two-Face/Harvey Dent from DC Comics 


\section{Witch 9}

\section{Appendix B}

Sample Case Study of Elphaba Thropp, "The Wicked Witch of the West"

Elphaba Thropp, better known as the Wicked Witch of the West, is a person of color, who was ostracized since childhood because of it. She developed anti-social and, eventually, aggressive tendencies, yet developed a special attachment to animals. One day, she and other students were expected to conduct a cruel experiment on a lion cub, but Elphaba unleashed magical abilities to save the animal. She was asked to meet the Wizard of Oz, only to discover that he, too, used animals, monkeys in this case, in cruel and unethical ways. Irate, she swore to enact vengeance on the Wizard and emancipate his monkey servants.

Years later, Elphaba was confronted with several traumas. Her sister was killed in a freak accident, and during an argument with a former friend named Glinda, Elphaba was tricked and trapped. Her lover was taken away from her, beaten viciously, and left to stand in a field for eternity. What's more, she learned that the Wizard sent his minions to kill her. In an attempt to protect herself and her animal friends, she used violent magic.

Elphaba's patterns of extreme rage and violence stemmed from a traumatic childhood, during which she was bullied and discriminated against. This rage, paired with a sense of duty towards animals, led Elphaba to perpetrate atrocities in the name of animal activism.

Additionally, an adversarial relationship with the Wizard and a death in her family seem to have exacerbated her already aggressive, anti-social behavior. To address and perhaps have prevented such behavior, implementing diversity training and anti-bullying measures in her school would have been desirable. In addition, animal-cruelty laws should have been adhered to, and social support resources, including grieving assistance, made available.

*Case study based on McGuire (1995). 